УДК 311.11

\author{
Коваленко Анастасия Игоревна \\ студент
}

Киевского национального университета имени Тараса Шевченко

\title{
ЧЕЛОВЕЧЕСКИЙ КАПИТАЛ КАК ОБЪЕКТ СТАТИСТИЧЕСКОГО ИССЛЕДОВАНИЯ
}

\begin{abstract}
Аннотация. B современных условиях развития экономических проиессов, возникают новые области и сферы деятельности. Инновационный характер работы экономических субъектов, потребности в новых видах ресурсов новых форм экономики требуют перехода на эффективные способы ведения бизнеса. Так, на сегодня важным стали знание и информация как основные формы проявления человеческого капитала. А человеческий капитал стал тем ресурсом, владение которым создает безусловные преимущества получения потенщиала развития $u$ устойчивого роста субъекта хозяйствования. Статистические исследования как способы динамической оценки помогают качественно оценивать человеческий капитал и прогнозировать потенциал его роста.

Ключевье слова: знание, индивид, институт, информация, капитал, потенциал, человеческий капитал, развитие экономики, статистическая оченка.
\end{abstract}

Актуальность. Человеческий капитал в современных условиях хозяйствования является одним из главенствующих направлений прогрессивного развития, как отдельных экономических единиц, так и экономики в целом. Так, в связи с требованиями внешней среды и ее 
непосредственным изменчивым воздействием на стороны хозяйствования экономических субъектов, возникает необходимость исследования человеческого капитала, а также вопроса важности выбора правильного подхода к его изучению. Актуальность исследования человеческого капитала также объясняется повышением важности человеческих ресурсов и высоким возможностям наращивания человеческого потенциала при грамотном подходе к его управлению.

Проблематика исследования. Актуальность проблемы управления человеческим капиталом сквозь призму статистического исследования обусловлена тенденцией перехода экономических процессов на более сложный уровень построения. Современные экономические процессы в многом объясняются и качественно прогнозируются благодаря изучению ряда признаков, которые удобно исследовать в динамическом аспекте. Согласно этим причинам исследованию большого массива информации в помощь приходят статистические методы анализа и оценки.

Цель работы. Таким образом, следует изучить человеческий капитал с позиции экономического понимания, а также стоит рассмотреть причины выбора большинством современных исследователей именно статистических методов оценки.

Изложение основного материала исследования. Как показывает практика, наиболее развитые экономические структуры работают с высокой организационной и экономической эффективностью в долгосрочном пути развития отчасти благодаря высоким показателям человеческого капитала. В рамках деятельности отдельных экономических единиц происходит смена технологий, усиление конкуренции, повышение требований со стороны к уровню квалификации персонала и прочим другим факторам. 
Существует невероятное многообразие подходов к определению человеческого капитала. Теоретические положения активно развиваются, и часто случается, что ученые и исследователи расходятся во мнении относительно определения понятий и выбирают свои варианты. При этом, сохраняется определенная общая направленность понимания категории даже при различном представлении информации, а различные варианты экономических понятий понятия сохраняют сопоставимость. Поэтому в целом вполне объяснимы способы выбора классификации подходов к определению человеческого капитала, или систематизации определений исследователей. В труде одного экономиста А. К. Нестерова, по нашему мнению, собраны в удобном для понимания смысле и формате основные направления исследований зарубежных и отечественных авторов. Определения понятий «человеческий капитал» представлены в таблице 1.

Безусловно, не правильным будет привести все множество определений и точек зрения к нескольким теоретическим подходам, выявление определенных общих характеристик дает возможность их свести в общую классификацию для дальнейшего сопоставления и изучения. Выделение общих признаков и групп определений позволит удобнее разобраться в большом количестве исследований человеческого капитала. Исследование показало, что на современном этапе направление изучения человеческого капитала активно развивается, а комплексное изучение всех теорий и подходов вызывает некоторые сложности [6]. 


\section{Таблииа 1}

\section{Определение понятия человеческого капитала различными авторами}

\begin{tabular}{|c|c|}
\hline Автор & Определение понятия человеческого капитала \\
\hline Т. Шульц & $\begin{array}{l}\text { Все человеческие ресурсы и способности являются или врожденными, или } \\
\text { приобретенными. Каждый человек рождается с индивидуальным } \\
\text { комплексом генов, определяющим его врожденный человеческий потенциал. }\end{array}$ \\
\hline Г. Беккер & $\begin{array}{l}\text { Человеческий капитал - это имеющийся у каждого запас знаний, навыков, } \\
\text { мотиваций. Инвестициями в него могут быть образование, накопление } \\
\text { профессионального опыта, охрана здоровья, географическая мобильность, } \\
\text { поиск информации. }\end{array}$ \\
\hline А. Смит & $\begin{array}{l}\text { Человеческий капитал - это приобретенные и полезные способности, } \\
\text { включая образование, уровень квалификации, профессионализм, } \\
\text { предпринимательские способности. }\end{array}$ \\
\hline Л.И. Абалкин & $\begin{array}{l}\text { Человеческий капитал как сумма врожденных способностей, общего и } \\
\text { специального образования, приобретенного профессионального опыта, } \\
\text { творческого потенциала, морально психологического и физического } \\
\text { здоровья, мотивов деятельности, обеспечивающих возможность приносить } \\
\text { доход }\end{array}$ \\
\hline $\begin{array}{l}\text { Р.И. } \\
\text { Капелюшников }\end{array}$ & $\begin{array}{l}\text { Под человеческим капиталом понимается капитал, в форме врожденных } \\
\text { способностей и таланта; интеллектуального запаса знаний, приобретенного } \\
\text { человеком в результате обучения или на основе практического опыта; } \\
\text { состояния здоровья, как некой совокупности врожденных характеристик, так } \\
\text { и вложений в его сохранение, восстановление и поддержание в течение } \\
\text { жизни. }\end{array}$ \\
\hline $\begin{array}{l}\text { А.Н. Добрынина } \\
\text { и С.А. Дятлова }\end{array}$ & $\begin{array}{l}\text { Человеческий капитал представляет собой } \\
\text { производительных сил человека в рыночной экономике, адекватную форму } \\
\text { организации производительных сил человека, включенных в систему } \\
\text { социально ориентированной рыночной экономики в качестве ведущего, } \\
\text { творческого фактора общественного воспроизводства }\end{array}$ \\
\hline
\end{tabular}

Источник: составлено автором на основании источника [3; 5]

Таким образом, выберем четыре подхода к определению значения человеческого капитала (см. табл. 2) [8].

Понятие человеческого капитала тесно связано с понятием потенциала. Это объясняется тем, что человеческий капитал - это своеобразный ресурс, который несет потенциальную возможность быть эффективным с 
наращением силы воздействия на аспекты его применения и способным находить новые резервы и возможности роста и развития.

В словаре иностранных слов значение «потенциал» - это степень мощности (уровень скрытых возможностей) в определенном отношении [1].

Таблииа 2

Общие подходы к определению человеческого капитала [8]

\begin{tabular}{|c|c|}
\hline Название подхода & Сторонники указанного подхода \\
\hline Человеческий капитал - это инвестиции & Т. Шульц , Г. Беккер, Г. Курчеева, Н. Кадыкова \\
\hline $\begin{array}{l}\text { Человеческий капитал - это набор } \\
\text { способностей, умений, знаний и навыков, } \\
\text { который может приносить доход }\end{array}$ & $\begin{array}{l}\text { Э. Долан и Дж. Линдсей, Р. Капелюшников, C. } \\
\text { Дятлов, Дж. Коулман, Stroombergen A., Rose D., } \\
\text { Nana G., Б. Генкин, Л. Абалкин, Т. Мясоедова, } \\
\text { Г. Тугускина, Р. Нуреев }\end{array}$ \\
\hline $\begin{array}{l}\text { Человеческий } \quad \text { капитал } \\
\text { совокупность активов }\end{array}$ & Х. Ксенофонтова \\
\hline $\begin{array}{l}\text { Человеческий капитал }- \text { это фактор } \\
\text { производства }\end{array}$ & $\begin{array}{l}\text { Ю. Корчагин, Д. Тимчишин, В. Калачев, Д. } \\
\text { Асланов }\end{array}$ \\
\hline
\end{tabular}

Если спроецировать это значение к индивиду, то можно говорить о потенциале как о возможности человека проводить какие-либо действия, проявлять определенную активность. А проявить свою активность в определенной деятельности человек может по-разному (рис. 1). Это касается простого физического труда, интеллектуальной деятельности, связанной с принятием решений, творческого направления, результатом чего становятся новые идеи, рационализаторские предложения и инновационные решения. Также могут быть и другие формы проявления человеческой активности в процессе его продуктивной деятельности. На рисунке 1 представлен состав человеческого потенциала индивида. 


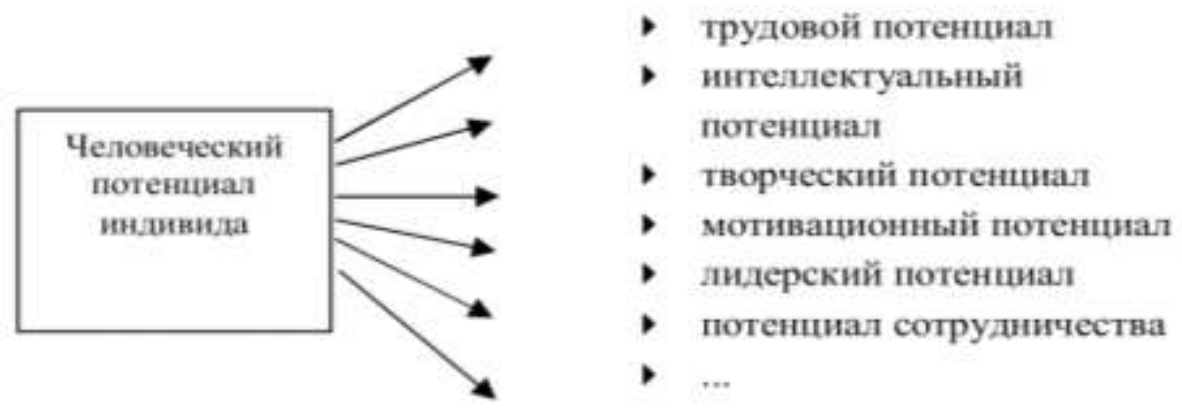

Рис. 1. Элементы человеческого потенциала индивида [3]

Отметим, что считаем неверным считать точной структуру человеческого потенциала для каждого индивида. Это объясняется некоторыми рассуждениями.

То есть, с одной стороны, в действительности выделить одну форму реализации человеческой активности от другой формы бывает достаточно сложно. В то же время, мы полагаем, что может существовать бесконечное множество различных форм в процессе деятельности, а сведение их к конкретным нескольким формам только ограничивает исследование.

Таким образом, мы будем говорить в данном исследовании, что человеческий потенциал индивида - это все возможные реальные и потенциальные возможности человека, которые используются им в процессе продуктивной жизнедеятельности в определенных условиях хозяйствования.

Понимая всю глубину исследования выбранной проблематики, мы можем перейти к аргументации эффективности использования статистического способа оценки человеческого капитала. Место статистического исследования в процессе изучения человеческого капитала можно представить сквозь призму применения результатов исследования человеческого капитала как элемента экономического исследования. Так, в экономике выделяют различные формы ее проявления и можно оценить место и роль человеческого капитала среди этих образований. Начнем с 
выбора форм экономики и важности человеческого капитала в каждой их них.

Таблица 3

\section{Взаимосвязь форм экономики и важности для них человеческого}

капитала

\begin{tabular}{|c|c|c|c|}
\hline $\begin{array}{c}\text { Формы } \\
\text { современной } \\
\text { экономики, } \\
\text { встречающиеся } \\
\text { в литературе } \\
\end{array}$ & Автор & $\begin{array}{c}\text { Подход к оценке важности } \\
\text { человеческого капитала }\end{array}$ & $\begin{array}{c}\text { Место проблематики в } \\
\text { статистическом исследовании }\end{array}$ \\
\hline $\begin{array}{l}\text { Постиндустриаль } \\
\text { ная экономика }\end{array}$ & $\begin{array}{l}\text { К. Кларк, Ж. } \\
\text { Фурастье, Д. } \\
\text { Белл }\end{array}$ & $\begin{array}{l}\text { Важность оценки человеческого } \\
\text { капитала обусловлена } \\
\text { качественно новым характером } \\
\text { человеческой деятельности и } \\
\text { накопления её существенности в } \\
\text { области сферы услуг. Поскольку } \\
\text { в такой форме экономики } \\
\text { наблюдается снижение роли } \\
\text { материального производства и } \\
\text { развитие сектора услуг и } \\
\text { информации, иной характер } \\
\text { человеческой деятельности, } \\
\text { опирающийся на другие виды } \\
\text { ресурсов, а также в связи с новой } \\
\text { моделью существующей } \\
\text { социальной структуры. }\end{array}$ & $\begin{array}{l}\text { Интегральный учет всех } \\
\text { факторов, в той или иной } \\
\text { степени влияющих на } \\
\text { динамику показателей, и } \\
\text { простота прогнозирования. Как } \\
\text { результат - оценка } \\
\text { человеческого капитала с } \\
\text { учетом перехода экономики в } \\
\text { новую модификацию. }\end{array}$ \\
\hline $\begin{array}{l}\text { Информационная } \\
\text { экономика }\end{array}$ & $\begin{array}{l}\text { М. Порат, Т. } \\
\text { П. Николаева }\end{array}$ & $\begin{array}{l}\text { В информационной экономике } \\
\text { определяющим } \\
\text { производительным ресурсом } \\
\text { выступает информация как } \\
\text { непосредственный продукт } \\
\text { интеллектуальной деятельности. } \\
\text { Информатизация изучается как } \\
\text { особая характеристика } \\
\text { производительных способностей } \\
\text { человека, образующих фонды } \\
\text { человеческого капитала. }\end{array}$ & $\begin{array}{l}\text { Работа метода на большом } \\
\text { массиве данных, большой } \\
\text { совокупности значений, что } \\
\text { делает оценку более точной и } \\
\text { информативной }\end{array}$ \\
\hline Новая экономика & $\begin{array}{l}\text { М. Келли, М. } \\
\text { Кастельс, И. }\end{array}$ & $\begin{array}{l}\text { В новой экономике с ростом } \\
\text { Значения такого фактора, как }\end{array}$ & $\begin{array}{l}\text { Статистическая оценка } \\
\text { предполагает интегральный }\end{array}$ \\
\hline
\end{tabular}




\begin{tabular}{|c|c|c|c|}
\hline & А. Стрелец & $\begin{array}{l}\text { человеческий капитал } \\
\text { (рассматриваем его как не } \\
\text { материализованный потенциал), } \\
\text { значение материального } \\
\text { потенциала только растет. При } \\
\text { этом, материальный потенциал } \\
\text { основан на активном участии } \\
\text { человеческого капитала. }\end{array}$ & $\begin{array}{l}\text { учет всех факторов, в той или } \\
\text { иной степени влияющих на } \\
\text { динамику результативного } \\
\text { показателя }\end{array}$ \\
\hline $\begin{array}{l}\text { Экономика } \\
\text { свободного } \\
\text { времени }\end{array}$ & $\begin{array}{l}\text { Данная форма } \\
\text { современной } \\
\text { экономики - } \\
\text { это } \\
\text { неразработанн } \\
\text { ая } \\
\text { экономическа } \\
\text { я концепция }\end{array}$ & $\begin{array}{l}\text { Новая экономика использует } \\
\text { новые формы ресурсов, отчасти и } \\
\text { состояние человеческого } \\
\text { капитала. Базой свободного } \\
\text { времени является высокий } \\
\text { уровень развития человеческого } \\
\text { капитала, дающего относительно } \\
\text { высокую эффективность } \\
\text { свободного времени. }\end{array}$ & $\begin{array}{l}\text { Статистическое моделирование } \\
\text { позволяет } \\
\text { сравнительно несложно } \\
\text { учитывать различные законы } \\
\text { распределения времени }\end{array}$ \\
\hline $\begin{array}{l}\text { Экономика на } \\
\text { знаниях }\end{array}$ & $\begin{array}{l}\text { Ж. Сапир, Д. } \\
\text { Куа, Т. Сакайя }\end{array}$ & $\begin{array}{l}\text { Важность человеческого } \\
\text { капитала проявляется через } \\
\text { способности индивида } \\
\text { генерировать новые знания и на } \\
\text { основе этого создавать новую } \\
\text { ценность. }\end{array}$ & $\begin{array}{l}\text { Статистические методы } \\
\text { предполагают возможность } \\
\text { качественного } \\
\text { прогнозирования, что дает } \\
\text { возможности предполагать } \\
\text { степень наращения нового } \\
\text { знания как новой ценности }\end{array}$ \\
\hline $\begin{array}{l}\text { Интеллектуальная } \\
\text { экономика }\end{array}$ & $\begin{array}{l}\text { Л. Эдвинссон, } \\
\text { М. Мэлоун, Т. } \\
\text { Стюарт }\end{array}$ & $\begin{array}{l}\text { Интеллектуальный капитал } \\
\text { напрямую связан с человеческим } \\
\text { капиталом, а их формирование } \\
\text { связано с определёнными } \\
\text { инвестициями. Здесь внимание } \\
\text { уделяется интенсивным } \\
\text { инвестициям в человеческий } \\
\text { капитал и в информационные } \\
\text { технологии }\end{array}$ & $\begin{array}{l}\text { Статистическая оценка требует } \\
\text { использования новых } \\
\text { информационных продуктов и } \\
\text { технологий, что делает анализ } \\
\text { более сложным с одной } \\
\text { стороны, но более точным и } \\
\text { много информативным - с } \\
\text { другой. }\end{array}$ \\
\hline
\end{tabular}

Источник: составлено автором по материалам: [3; 5, с. 33; 7]

Таким образом, в каждой экономической системе и при выборе в качестве ресурса человеческого капитала имеет место быть и статистическое исследование. Статистический подход дает возможность провести исследование с соблюдением важных принципов: учет множества факторов, 
влияющих на результативные значения человеческого капитала; учет временных характеристик значений, использование динамических рядов исследования, рассмотрение прогнозных моделей и прочее.

На основании изложенного выше материала, можем составить схему взаимосвязи главных компонент человеческого потенциала (рис. 2).

И так, человеческий капитал выступает связующим элементом модификации нового знания индивида и общей экономической эффективности институтов различных форм экономики. Таким образом, можно наблюдать как человеческий капитал как форма знания и информации присутствует в различных сферах экономической области, создавая потенциал роста экономической системы и общего прогресса общества.

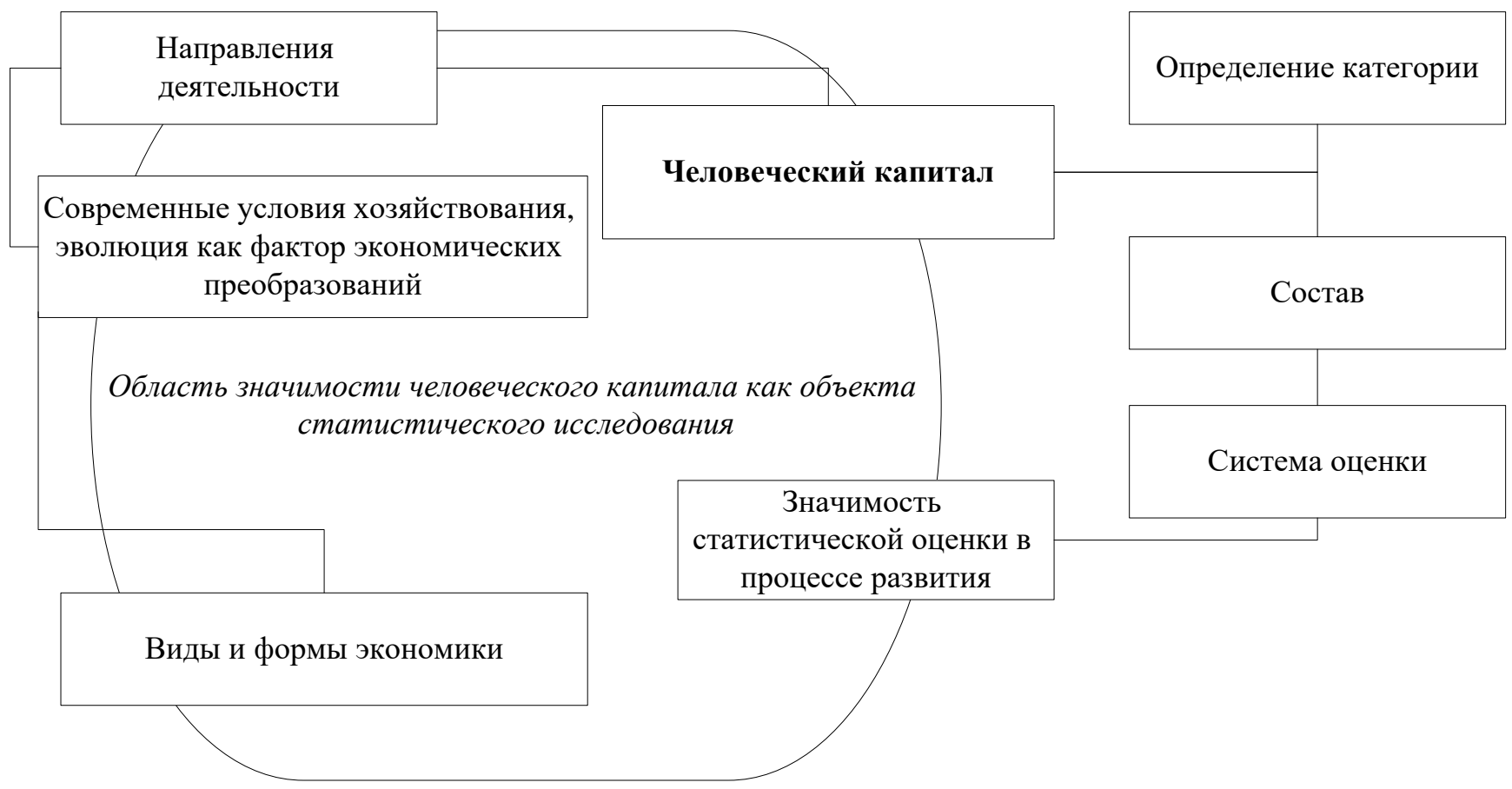

Рис. 2. Место человеческого капитала как объекта статистического исследования Источник: разработано автором

Ученые-исследователи сходятся во мнении, что важным фактором, отражающим состояние и степень развития национальной экономики, 
является экономический потенциал, в основе которого лежит человеческий капитал, отражающий способность отдельных институтов функционировать в мировой экономической системе. Множество преимуществ и условий эффективного роста субъектов, работы и развития экономики на знаниях и информации принадлежат тем экономическим единицам, которые имеют определенный уровень накопления качественного человеческого капитала [2].

Чем выше уровень знания, чем выше качество накопленного человеческого капитала, чем большим есть багаж информации и способности еe наращения в дальнейшем, тем больше будет перспективы технологического обновления производства, рыночных реформирования к более эффективным формам функционирования, повышения уровня жизни населения в целом.

Выводы. Современные научные труды посвящены рассмотрению человеческого фактора как определяющего в инновационном развитии экономических институтов. В современных условиях хозяйствования природный и финансовый ресурсы не являются первостепенными факторами производства. Сегодня таким фактором выступает человек, поскольку новейшие отрасли требуют глубоких знаний, навыков, умений, которыми обладает человек. Кроме того, в человеческом ресурсе скрываются наибольшие резервы для повышения эффективности функционирования инновационной экономики.

Исследования ученых и практический опыт показали, что национальное богатство общества зависит от характера занятий людей, их способности к труду, а эффективность развития экономики современных государств в наибольшей степени зависит от средств, вкладываемых в человеческий ресурс. 


\section{Литература}

1. Богатырева В.В. Управление человеческим капиталом в инновационной экономике // Економічний вісник Донбасу. - 2013. № 1 (31). - С. 221235.

2. Болотин А. А. Человеческий капитал как фактор экономического развития современного предприятия // Вопросы экономики. - 2011. - № 46 (88). - C. $13-20$.

3. Гуськова Н. Д. Дорофеев В. Д. Человеческий капитал: теория и практика управления в социально-экономических системах: монография / Под общ. ред. Р.М. Нижегородцева и С.Д. Резника. - М.; ИНФРА-М, 2014. - 310 c.

4. Даниленко, Н. Н. Формирование человеческого капитала/ Н. Н. Даниленко, И. С. Долгополова. - Иркутск: Издательство БГУЭП, 2009. 119 c.

5. Нестеров, А. К. Человеческий капитал [Электронный ресурс] / А. К. Нестеров // Образовательная энциклопедия ODiplom.ru. - Режим доступа: http://odiplom.ru/lab/chelovecheskii-kapital.html (дата обращения: 16.04.2018).

6. Полякова Е. М. Качество человеческого капитала как фактор модернизации общества. / Статьи и тезисы докладов 1-го Международного Конгресса «Модернизация экономики России: итоги и перспективы» / Южно-Российский государственный университет экономики и сервиса (ЮРГУЭС), 2-3 ноября 2011. - Пятигорск, 2011. 0,1 п.л. Есипов А. А. Сущность и функции конкурентного потенциала на предприятии // Молодой ученый. - 2016. - №8. - С. 536-540 [Электронный $\quad$ pecypc]. https://moluch.ru/archive/112/28761/ (дата обращения: 17.02.2019). 
7. Солодухина О. И. Разработка методики оценки эффективности формирования и использования человеческого капитала / О. И. Солодухина, М. А. Пархомчук // Экономические науки, - 2016, - №3 (136). - C. 30-33.

8. Хмелева, Г. А. Человеческий капитал как условие формирования инновационной экономики региона / Г. А. Хмелева. - Самара: САГМУ, 2012. - C. 42. 